\title{
Assessment of water pollution near the deep oil seep in Lake Baikal
}

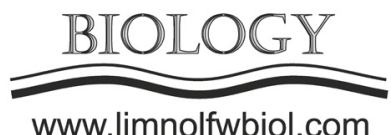

www.limnolfwbiol.com

\author{
Gorshkov A.G., Izosimova O.N.*, Pavlova O.N., Khlystov O.M., Zemskaya T.I. \\ Limnological Institute, Siberian Branch of the Russian Academy of Sciences, Ulan-Batorskaya Str., 3, Irkutsk, 664033, Russia
}

\begin{abstract}
Water purity was assessed at the site of a deep oil seepage near Cape Gorevoy Utes (Central Baikal). Polycyclic aromatic hydrocarbons (PAHs) and $n$-alkanes were determined in different types of oil-containing samples collected at this section of Lake Baikal. The set of studied samples included: (i) samples of water from the surface water layer; (ii) samples of water from different depths; (iii) oil on the water surface; (iv) oil from a sediment core. In the surface water layer and the water column, the total concentration of $n$-alkanes ranged from 0.2 to $5.3 \mu \mathrm{g} / \mathrm{L}$ and did not exceed the 0.1 maximum permissible concentration ( $\mathrm{MPC}_{\text {fish }}=50 \mu \mathrm{g} / \mathrm{L}$ ) established for hydrocarbons in water bodies of fishery importance. PAHs with carcinogenic properties were less than $0.1 \mathrm{ng} / \mathrm{L}$. The total concentration of PAHs found in the water column did not exceed $110 \mathrm{ng} / \mathrm{L}$; toxic equivalent (TEQ) values ranged from 0.001 to $0.110 \mathrm{ng} / \mathrm{L}$. The distribution of petroleum hydrocarbons from the seepage site was limited, and water pollution was localised. The low level of water pollution is associated with natural mechanisms in the Baikal ecosystem. Microbiological community and phytoplankton make a decisive contribution to the purity of Baikal water, and oil fractionation during deep discharge contributes to the bioavailability of petroleum hydrocarbons.
\end{abstract}

Keywords: Oil seeps Contamination of water Lake Baikal

\section{Introduction}

Natural oil seepage in freshwater lakes is associated with rift zones: Lake Tanganyika - with the East African Rift (Simoneit et al., 2000), Lake Chapala - with the Citala Rift (E-W) (Zarate-del Valle et al., 2006), and Lake Baikal - with the Baikal rift. High heat flux in the rift zone of Baikal $\left(76 \mathrm{~mW} / \mathrm{m}^{2}\right.$ on average, Golmshtok et al., 2000) contributes to the heating of sedimentary formations and stimulates the generation of hydrocarbons. According to data on seismic studies, oil and gas may accumulate in the structure of the Cenozoic sedimentary basins in Baikal, with a potential resource of 500 million tons (Kontorovich et al., 2007). The presence of oil is evidenced by natural oil seepage in the form of asphalt that appears along coastal cliffs or comes from depths of 10-15 $\mathrm{m}$ to the water surface of the lake approximately $300-500 \mathrm{~m}$ from the shore, forming oil slicks from the emerging tar balls with a diameter of up to $1.5 \mathrm{~m}$. In wintertime, oil accumulates under the ice, filling fractures in the ice cover. Examination of this oil indicates that it is an aromaticnaphthenic type, in which there are no normal alkanes, monomethyl alkanes or acyclic isoprenoids. The flow of petroleum hydrocarbons from the bottom of the lake is $0.1-5$ tons of heavy oil per year (Kontorovich et al., 2007).
In 2005, a new deep oil seepage was discovered near Cape Gorevoy Utes (Central Baikal). At this site, there were numerous oil slicks with a diameter of up to $1 \mathrm{~m}$. The oil collected at the time of its emergence on the water surface had an extremely high concentration of $n$-alkanes and was identified as non-biodegraded paraffin oil. The oil sampled from the water surface contained a full range of petroleum hydrocarbons: $n$-alkanes, $i$-alkanes, alkyl-cyclohexanes, isoprenoids (pristane and phytane), PAHs and hopanes as well as a complex of unique molecular biomarkers (Gorshkov et al., 2006; Kashirtsev et al., 2006; Khlystov et al., 2007; Kontorovich et al., 2007). In 2008, investigations of the bottom sites near the oil seepage using the MIR deep-sea manned submersibles at depths of 870-920 $\mathrm{m}$ revealed structures consisting of paraffin petroleum asphalt, through which oil discharged. At sites with a flat bottom and near these structures, there were accumulations of liquid oil droplets that floated without any periodicity (Khlystov et al., 2009).

According to estimates (Khlystov et al., 2007; Kontorovich et al., 2007), the amount of oil entering Baikal waters at this site does not exceed $4 \mathrm{t} / \mathrm{y}$, which is not comparable to the volumes of industrial oil discharged into the surface waters of the world's oceans during technological disasters (Hazen et al., 2010; Vila

*Corresponding author.

E-mail address: smileoc@mail.ru (O.N. Izosimova) 
et al., 2010; Yender and Stanzel, 2011). Nevertheless, constant oil emission, low water temperature and the long replacement period of lake water by tributaries (ca. 330 years) increase the environmental risk of a decline in Baikal water quality. It is also worth noting that natural oil seeps are dynamic systems that develop over time and are characterized by the unpredictability of the emergence of new seeps in time and space.

Lake Baikal is the globally important drinking water source containing $20 \%$ of the world's surface freshwater. To assess the purity of water in the area of deep oil seepage near Cape Gorevoy Utes, a natural source of oil hydrocarbons, samples of freshly emitted oil and oil slicks from the water surface as well as the water samples from various layers in the water column were collected. A bottom sediment core was also sampled in the area of deep oil seepage. In all samples of oil, water, and bottom sediments, $n$-alkanes and PAHs were studied. $n$-Alkanes are the dominant components of oil entering the lake in this area. PAHs are a minor component of oil, but this class of substances is among the priority pollutants and subject to constant monitoring in the environment.

\section{Materials and methods}

Investigations were carried out in 2016 and 2019 at the site of the natural oil seepage near Cape Gorevoy Utes $(10 \mathrm{~km}$ from the coast, $900 \mathrm{~m}$ depth, Central Baikal; coordinates 53'18'33'N 108'23'46" E). Oil, water from the surface and deep layers, and bottom sediments were sampled on board the research vessel "G. Yu. Vereshchagin" at seven stations, R4 R10 (Fig. 1). Stations R4, R5, R7 - R10 were located at sites with oil slicks on the surface; station R6 was at a site without oil slicks. Oil slicks were sampled using a sterile beaker and poured into $1 \mathrm{~L}$ glass bottles. Water samples were taken using an SBE 32 Carousel Water Sampler from depths of 0, 5, 200, 400, 600, 800, and $860 \mathrm{~m}$ and poured into $1 \mathrm{~L}$ glass bottles. Fifty $\mathrm{mL}$ of dichloromethane was added to each water sample; then the mixture was shaken, covered with a lid with aluminium foil and stored at $+5{ }^{\circ} \mathrm{C}$ until analysis.

The bottom sediment core was sampled at the VER-16-01 (GC4) station using a gravity corer with a plastic liner. The upper part of the core (from the surface down to $140 \mathrm{~cm}$ ) contained gas-saturated aleuropelitic muds impregnated with oil; the lower part (from 140 to $310 \mathrm{~cm}$ ) was clay, in which there were vertical or inclined discharge channels with diameters of up to $5 \mathrm{~mm}$, split and degasification cracks of 1-2 mm, and horizontal aleuro-sandy interlayers also impregnated with oil.

Normal hydrocarbons and PAHs in water samples were determined by liquid-liquid extraction with dichloromethane. Before extraction, $100 \mu \mathrm{L}$ of PAH solution (a mixture of naphthalene- $d_{8}$, acenaphthene- $\mathrm{d}_{10}$, phenanthrene- $\mathrm{d}_{10}$, chrysene- $\mathrm{d}_{12}$, and perylene- $d_{12}$ ) in acetonitrile with a concentration of 5 $\mathrm{ng} / \mu \mathrm{L}$ for each polyarene; $200 \mu \mathrm{L}$ squalane solution in dichloromethane with a concentration of $330 \mathrm{ng} / \mu \mathrm{L}$; and $25 \mathrm{~mL}$ dichloromethane were added to the water samples. The mixture was shaken for $3 \mathrm{~min}$ and moved to a $1 \mathrm{~L}$ separatory funnel. After phase separation, the lower dichloromethane layer was separated, and the extraction was repeated with a new $25 \mathrm{~mL}$ portion of extractant. The extracts were mixed and concentrated to a volume of $\sim 1 \mathrm{~mL}$. $\mathrm{Na}_{2} \mathrm{SO}_{4}$ (calcined and chemically

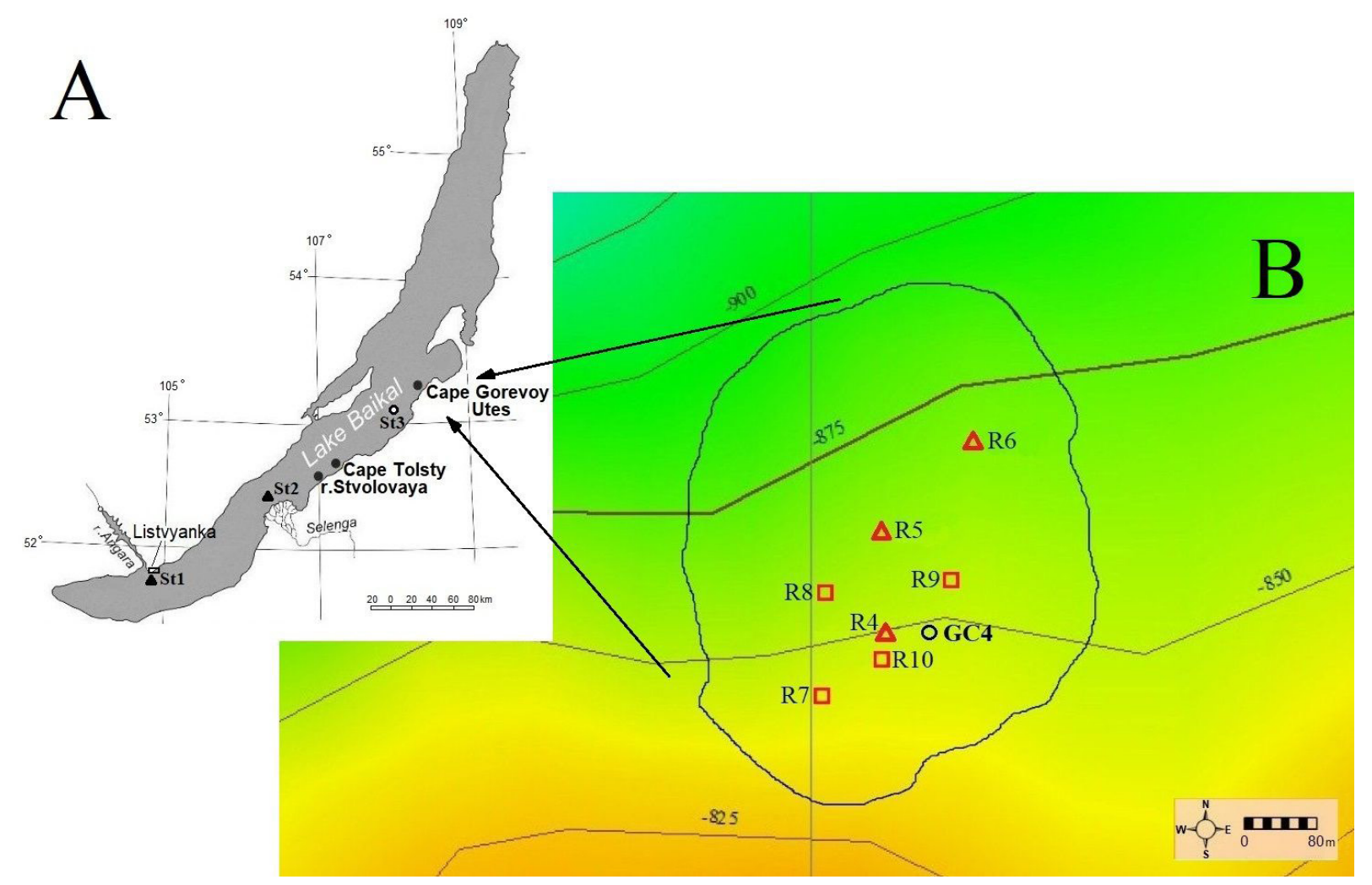

Fig. 1. Map of Lake Baikal: A - • - sites of oil seeps; O, $\mathbf{A}$ - reference stations; B - $\Delta, \square$ - sampling stations. 
pure) was added to the concentrate, and the mixture was shaken and centrifuged. The supernatant was transferred to the autosampler vials of the gas chromatography-mass spectrometer. The extracts of water samples containing oil (after chromatography analysis) were dried to constant weight; the resulting residue was weighed. The content of $n$-alkanes and PAHs in these samples was calculated relative to the amount of recovered oil.

To determine $n$-alkanes and PAHs in the bottom sediment core, samples that differed in maximum oil content were taken. The samples were dried at room temperature to constant weight and then homogenised. Two samples (2-3 g) were taken, to which internal standards of $25 \mu \mathrm{L}$ PAH solution and $50 \mu \mathrm{L}$ squalane solution were added. PAHs and $n$-alkanes were twice extracted with $15 \mathrm{~mL}$ of dichloromethane in an ultrasonic bath, each time for $20 \mathrm{~min}$. The extracts were mixed and centrifuged. The supernatant was taken and concentrated to a volume of $\sim 1 \mathrm{~mL}$; concentrate then was diluted with $n$-hexane in the ratio of methylene chloride: $n$-hexane $=1: 10(\mathrm{v} / \mathrm{v})$; the mixture was kept at $+5{ }^{\circ} \mathrm{C}$ for $24 \mathrm{~h}$, the sample was centrifuged, and the supernatant was transferred to the flask of the chromatography autosampler and concentrated under an argon flow to a volume of $\sim 0.1 \mathrm{~mL}$. The extracts of bottom sediment samples containing oil were dried to constant weight; the resulting residue was weighed. The content of $n$-alkanes and PAHs in these samples was calculated relative to the amount of recovered oil.

In the collected samples, $n$-alkanes and PAHs were determined: $n$-alkanes as homologous series from $\mathrm{C}_{8}$ to $\mathrm{C}_{30}$ and $24 \mathrm{PAH}$ compounds, including 16 priority polyarenes: naphthalene (Nap); 1-methylnaphthalene $(1 \mathrm{mNa})$; 2-methylnaphthalene $(2 \mathrm{mNa})$; acenaphthylene (Acy); acenaphthene (Ace); fluorene (Fl); phenanthrene $(\mathrm{Ph})$; anthracene (An); 1-metylphenanthrene (1mPh); 2-metylphenanthrene (2mPh); 3-metylphenanthrene $(3 \mathrm{mPh})$; 9-metylphenanthrene $(9 \mathrm{mPh})$; fluoranthene (Flu); pyrene (Pyr); benzo[a]anthracene (BaA); chrysene (Chr); benzo[b]fluoranthene (BbF); benzo[k] fluoranthene $(\mathrm{BkF})$; benzo[e]pyrene (BeP); benzo[a] pyrene (BaP); perylene (Per); indeno[1,2,3-cd]pyrene (InP); benzo[g,h,i]perylene (BghiP); and dibenzo[a,h] anthracene (DahA).

PAHs and $n$-alkanes in the samples were determined using an Agilent Technologies 7890B GC System 7000C GC-MS Triple Quadrupole Gas Chromatography-mass spectrometer with an OPTIMA ${ }^{\circledR}$ $17 \mathrm{MS}$ capillary column $(30 \mathrm{~m} \times 0.25 \mathrm{~mm} \times 0.25 \mu \mathrm{m})$. The GC operating parameters were from 50 to $310^{\circ} \mathrm{C}$ at a heating rate of $20 \% \mathrm{~min}$, then maintaining the column at the final stage at $310^{\circ} \mathrm{C}$ for $35 \mathrm{~min}$. The temperatures of the injector and ion source were $290{ }^{\circ} \mathrm{C}$ and 250 ${ }^{\circ} \mathrm{C}$, respectively; the volume of the injected sample was $2 \mu \mathrm{L}$ without flow splitting, and the electron impact ionization energy was $70 \mathrm{eV}$. The chromatograms of sample extracts were recorded in the SCAN mode by scan mass spectrum from 50 to $600 \mathrm{~m} / \mathrm{z}$. Peaks were identified using the LIB2NIST v.1.0.0.8 mass spectral data conversion program for 150,000 compounds. For quantification of $n$-alkanes and PAHs, chromatograms of samples were recorded in the SIM mode: the peaks of $n$-alkanes with 57 and $71 \mathrm{~m} / \mathrm{z}$; the peaks of PAHs with $128,136,142,152,154,164,166,178,188,192,202$, $228,240,252,264,276$, and $278 \mathrm{~m} / \mathrm{z}$. The peaks were identified by relative retention times.

Quantification was performed using the internal standard method. The chromatograph was calibrated in the range of the expected $\mathrm{PAH}$ and $n$-alkane concentrations in the extracts with the preparation of solutions of PAHs and $n$-alkanes with a concentration of $0.05-50 \mathrm{ng} / \mathrm{mL}$. The calibration solutions were prepared by diluting the certified PAH and $n$-alkane mixture (Supelco, USA) with an $n$-hexane-acetone mixture $(1: 1, \mathrm{v} / \mathrm{v})$. The concentration of analytes in the samples was calculated as the average value of the results of two determinations in one sample. The PAH and $n$-alkane extraction efficiency were approximately $70 \%-80 \%$. Limit of detection (LOD) was calculated as the threefold standard deviation peak area of the PAH and $n$-alkane levels in procedure blanks, in the water: $\mathrm{PAH}-0.1-1.0 \mathrm{ng} / \mathrm{L}, n$-alkane $-2 \mathrm{ng} / \mathrm{L}$; in the oil: $\mathrm{PAH}$ - 1-10 ng/g, n-alkane - $100 \mathrm{ng} / \mathrm{g}$. Relative standard deviation (RSDs) for determining PAHs and $n$-alkanes was estimated within a range from $15 \%$ to $20 \%$ for individual analytes.

Toxic equivalents (TEQ) were calculated according to the following equation:

$$
\mathrm{TEQ}=\mathrm{C}_{\mathrm{i}} \mathrm{x} \mathrm{TEF}_{\mathrm{i}} \text {, }
$$

where $\mathrm{C}_{\mathrm{i}}$ is $\mathrm{PAH}$ concentration in $\mathrm{ng} / \mathrm{L}$, and $\mathrm{TEF}_{\mathrm{i}}$ are the toxicity coefficients for individual PAHs relative to BaP. The following TEFs were used for PAHs from Baikal waters: 0.001 for Na, Acy, Ace, Fl, Ph, Flu, and Pyr; 0.01 for An and Chr; and 0.1 for BbF (Nisbet and LaGoy, 1992).

\section{Results and discussion}

\section{1. n-Alkanes and PAHs in oil on the water surface and bottom sediments}

n-Alkanes, isoprenoids (pristane and phytane) and PAHs were identified in the composition of freshly emitted oil on the water surface. Moreover, $n$-alkanes were the dominant component in the oil. In the oil slicks, total concentrations of $n$-alkanes $\left(\Sigma_{\text {alk }}\right)$ and PAHs $\left(\Sigma_{\mathrm{PAH}}\right)$ were low, up to four times lower than in freshly emitted oil (Table 1). In the slicks, $n$-alkanes are represented by homologous series $\mathrm{C}_{12}-\mathrm{C}_{26}$. The ratio of light and heavy homologues in this series $\left(\mathrm{R}_{\text {alk }}=\Sigma\left[\mathrm{C}_{8}-\mathrm{C}_{18}\right] / \Sigma\left[\mathrm{C}_{19}-\mathrm{C}_{29}\right]\right.$ $\geq 0.7$ ) indicated a partial loss of the light fraction. Records of an unresolved complex mixture (UCM) of branched and cyclic hydrocarbons on chromatograms of slick samples and a decrease in naphthalenes in the PAH fraction confirmed oil deformation on the surface of the lake resulting from evaporation and weathering. PAHs detected in oil on the water surface included 20 compounds. $\mathrm{PAH}$ ratios, $\mathrm{An} /(\mathrm{An}+\mathrm{Ph})$ and $\mathrm{Flu} /$ (Flu + Pyr), indicated a petrogenic source of oil (Yunker et al., 2002), and ratios of isoprenoids (pristane/ phytane) in oil slicks corresponded to those in the freshly emitted oil. 
Table 1. Features of the oil on the water surface

\begin{tabular}{|l|c|c|}
\hline \multicolumn{1}{|c|}{ Feature } & $\begin{array}{c}\text { Freshly emitted oil on } \\
\text { the water surface }\end{array}$ & $\begin{array}{c}\text { Oil slicks on the water } \\
\text { surface }\end{array}$ \\
\hline Homologous series of $n$-alkanes & $\mathrm{C}_{8}-\mathrm{C}_{29}$ & $\mathrm{C}_{13}-\mathrm{C}_{26}$ \\
$\Sigma_{\text {alk }}, \%$ & 90 & $21-24$ \\
$\mathrm{R}_{\text {alk }}=\Sigma\left[\mathrm{C}_{8}-\mathrm{C}_{18}\right] / \Sigma\left[\mathrm{C}_{19}-\mathrm{C}_{29}\right]$ & 1.0 & $0.7-0.9$ \\
The $\mathrm{Pr} / \mathrm{Ph}$ ratio & 6.7 & $6.1-6.8$ \\
$\Sigma_{\mathrm{PAH}}, \mathrm{ppm}$ & 1500 & $530-650$ \\
$\Sigma_{\text {naph }}, \%$ of total PAHs & 32 & $5.0-25$ \\
$\mathrm{BaP}$ number, ppm & 3.7 & $5.1-5.6$ \\
The An/(An $+\mathrm{Ph}$ ) ratio & 0.09 & 0.04 \\
The Flu/(Flu $+\mathrm{Pyr}$ ) ratio & 0.34 & $0.28-0.33$ \\
\hline
\end{tabular}

Station R6 (Fig. 1) differed by the lack of surface oil slicks. Nevertheless, $n$-alkanes $\left(\mathrm{C}_{12}-\mathrm{C}_{26}\right)$ and PAHs (14 compounds) were found in surface water samples (Table 2). High molecular weight homologues dominated in the fraction of $n$-alkanes $\left(\Sigma_{\text {alk }} 0.2-5.3\right.$ $\mu \mathrm{g} / \mathrm{L} ; \mathrm{R}_{\text {alk }}=0.7$ ). In the composition of PAHs, unlike that of oil films, there were no high molecular weight PAHs: the content of Per, InP, BghiP, and DahA were below the limit of their quantification $(0.1 \mathrm{ng} / \mathrm{L})$; the total concentration of naphthalenes $\left(\Sigma_{\text {naph }}\right)$ corresponded to a range from 4.1 to $32 \mathrm{ng} / \mathrm{L}\left(30 \%-63 \%\right.$ of $\left.\Sigma_{\mathrm{PAH}}\right)$.

In the fractures and interlayers of the bottom sediment core, the amount of oil was minimal, up to $2.9 \%$ of the core mass, and the $\Sigma_{\text {alk }}$ concentration varied from 0.10 to $1.4 \%$ (Table 3 ). In the oil from upper layers of the core (samples from 0.40 and $50 \mathrm{~cm}$ layers) high molecular weight paraffins dominated, apparently resulting from the migration of the light fraction to the lake water. The oil composition in the core sample from a deep layer $(274 \mathrm{~cm}$ ) showed an equal ratio of light and high molecular homologues of $n$-alkanes (a series from $\mathrm{C}_{13}$ to $\mathrm{C}_{29}$ ). PAHs identified in the oil from the core contained 24 compounds ( $\Sigma_{\mathrm{PAH}} 400-1400 \mathrm{ppm}$ ), including high molecular weight polyarenes at a level of $<0.1-10 \mathrm{ppm}$. The amount of BaP in the core samples did not exceed 3.2-9.8 ppm. The PAH composition and ratio of indicator polyarenes corresponded to those in the freshly emitted oil on the water surface.

\section{2. n-Alkanes and PAHs in the water column}

In the water column (5-860 $\mathrm{m}$ at stations $\mathrm{R} 4$, R5, R7 - R10), normal hydrocarbons are identified as homologous series from $\mathrm{C}_{12}$ to $\mathrm{C}_{27}$, with the $\Sigma_{\text {alk }}$ concentration ranging from 0.2 to $4.5 \mu \mathrm{g} / \mathrm{L}$ (Table 2). The average value $\Sigma_{\text {alk }}$ concentration is $1.6 \mu \mathrm{g} / \mathrm{L}$, and 1.5 times higher than the median value, indicating a heterogeneous distribution of alkanes in the water column. At station R6 (station distinguished by the lack of surface oil slicks), the $\Sigma_{\text {alk }}$ content in water samples from the 5-860 $\mathrm{m}$ layer corresponded to a narrow range of values, from 0.2 to $0.9 \mu \mathrm{g} / \mathrm{L}$; low molecular weight homologues dominated most of the samples. At station R4, layers of 200, 600, and $800 \mathrm{~m}$ had a significant content of high homologues (Fig. 2).
The PAH fraction in the water column (5-800 m layer at stations R4 - R10) had a narrow series of low molecular weight polyarenes, including $\mathrm{Na}$, Ace, Fl, Ph, Flu, and Pyr. In single samples, there were Acy, Chr, $\mathrm{BbF}$, and BeP. The total number of naphthalenes $\left(\Sigma_{\text {naph }}\right)$ had a maximum proportion (up to $85 \%$ ) in the total $\Sigma_{\mathrm{PAH}}$ concentration, which was within the range from 1.0 to $110 \mathrm{ng} / \mathrm{L}$ (Table 2). At station R6, the content of PAHs in water samples differed in a narrow range of detected concentrations, from 3.9 to $15 \mathrm{ng} / \mathrm{L}$.

It is worth noting that extreme concentrations of $n$-alkanes and PAHs were detected in the water sample from the $200 \mathrm{~m}$ layer at station R4, in which the $\Sigma_{\text {alk }}$ concentration reached $330 \mu \mathrm{g} / \mathrm{L}$, and $\Sigma_{\mathrm{PAH}}$ concentration reached $100 \mathrm{ng} / \mathrm{L}$. Normal hydrocarbons were represented by a series from $\mathrm{C}_{13}$ to $\mathrm{C}_{29}$, with a dominance of high molecular weight homologues, similar to the $n$-alkane content in samples from the upper layers of the core. The PAH concentration in this sample was also higher than in the samples from other layers of the water column (by an order of magnitude), and the content of naphthalenes in the fraction was estimated at the maximum level, up to $85 \%$ of the $\Sigma_{\text {PAH }}$ concentration.

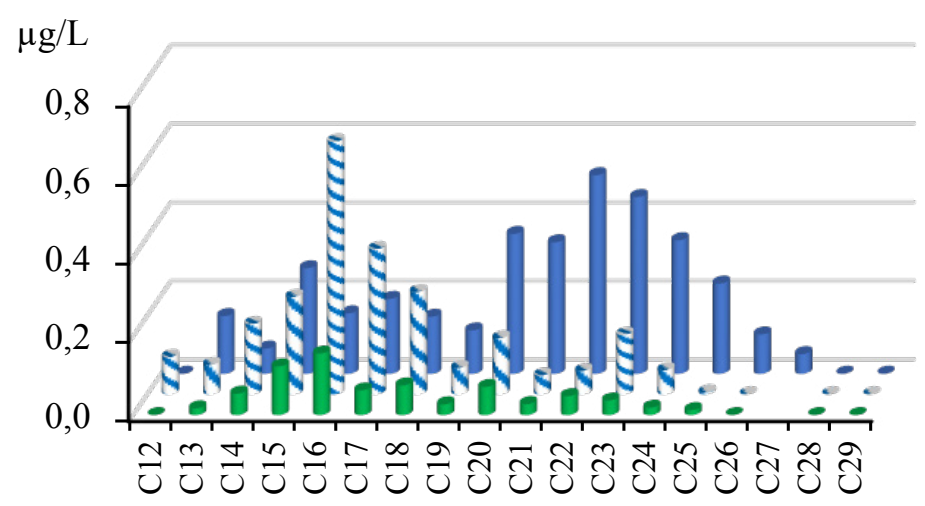

n-Alkanes

Fig. 2. A ratio of homologues of n-alkanes in water extracts from the $600 \mathrm{~m}$ layer:

- station R4; $\Sigma$ alk $=3.4 \mu \mathrm{g} / \mathrm{L} ;$ Ralk $=0.4 ;$
- station R5 $\left(\sum\right.$ alk $=2.4 \mu \mathrm{g} / \mathrm{L} ;$ Ralk $=3.5$.
- station R6 $\left(\sum\right.$ alk $=0.73 \mu \mathrm{g} / \mathrm{L} ;$ Ralk $=2.0$ 
Table 2. Content of $n$-alkanes and PAHs in the water column in 2016 and 2019

\begin{tabular}{|c|c|c|c|c|c|c|c|}
\hline \multirow{3}{*}{ Feature } & \multicolumn{7}{|c|}{ Water layer, m } \\
\hline & 0 & 5 & 200 & 400 & 600 & 800 & 860 \\
\hline & \multicolumn{7}{|c|}{ Stations R6 } \\
\hline$\Sigma_{\text {alk }}, \mu g l^{-1}$ & $0.2-5.3$ & 0.7 & $0.2-0.7$ & 0.7 & $0.2-0.7$ & $0.3-0.9$ & $0.2-0.4$ \\
\hline $\mathrm{R}_{\mathrm{alk}}$ & $0.7-0.8$ & 3.3 & $1.7-2.9$ & 2.1 & $0.7-2.0$ & $1.4-3.0$ & $1.0-4.3$ \\
\hline$\Sigma_{\mathrm{PAH}}, \mathrm{ng} \mathrm{l}^{-1}$ & $14-51$ & 5.4 & 4.7 & 10 & 15 & 14 & 3.9 \\
\hline$\Sigma_{\text {naph. }}, \mathrm{ng} \mathrm{l}^{-1}$ & $4.1-32$ & 3.1 & 3.0 & 9.0 & 5.0 & 4.1 & 3.1 \\
\hline $\mathrm{R}_{\mathrm{PAH}}^{* *}$ & 0.6 & 0.7 & 1.0 & 0.7 & 0.6 & 0.6 & 0.7 \\
\hline Feature & \multicolumn{7}{|c|}{ Stations R4, R5, R7 - R10 } \\
\hline$\Sigma_{\text {alk }}, \mu g 1^{-1}$ & - & $1.3-4.5$ & $\begin{array}{c}0.2-2.8 \\
(330 *)\end{array}$ & $0.8-4.0$ & $0.2-3.4$ & $0.3-2.6$ & $0.2-3.7$ \\
\hline $\mathrm{R}_{\mathrm{alk}}^{1}$ & - & $1.3-2.1$ & $0.6-1.2$ & $0.9-1.7$ & $0.4-3.2$ & $0.6-5.8$ & $1.0-3.2$ \\
\hline$\Sigma_{\mathrm{PAH}}, \mathrm{ng} \mathrm{l}^{-1}$ & - & $18-90$ & $18-100$ & $14-59$ & $7.2-62$ & $5.2-47$ & $12-110$ \\
\hline$\Sigma_{\text {naph. }}, \mathrm{ng} \mathrm{l}^{-1}$ & - & $5.7-67$ & $13-87$ & $3.2-7.9$ & $5.1-54$ & $3.3-32$ & $6.2-83$ \\
\hline $\mathrm{R}_{\mathrm{PAH}}{ }^{* *}$ & - & 0.6 & 0.6 & 0.6 & 0.5 & 0.6 & 0.6 \\
\hline
\end{tabular}

Note: " - the extreme concentration of $n$-alkanes; ${ }^{* *}$ - the ratio of the Flu/(Flu + Pyr) concentrations

Table 3. Features of the bottom sediment core, VER-16-01, GC.4

\begin{tabular}{|c|c|c|c|c|c|c|c|c|}
\hline \multirow{2}{*}{ Feature } & \multicolumn{8}{|c|}{ Core layer, $\mathrm{cm}$} \\
\hline & 0 & $10-15$ & 40 & 50 & 100 & 200 & 250 & 274 \\
\hline Moisture, \% & 70 & 60 & 61 & 63 & 60 & 46 & 40 & 40 \\
\hline Total carbon content, \% & 5.1 & 5.1 & 7.7 & 7.5 & 5.6 & 2.7 & 2.9 & 2.6 \\
\hline Oil content, \% & 0.47 & 0.64 & 2.5 & 2.9 & 0.20 & 0.18 & 0.36 & 0.34 \\
\hline$\Sigma_{\text {alk }}$ in oil, ppm & 1400 & 1700 & 780 & 1200 & 1500 & 920 & 3300 & 1400 \\
\hline $\mathrm{R}_{\mathrm{alk}}=\Sigma\left[\mathrm{C}_{8}-\mathrm{C}_{18}\right] / \Sigma\left[\mathrm{C}_{19}-\mathrm{C}_{29}\right]$ & 0.52 & - & 0.35 & 0.33 & - & - & - & 1.1 \\
\hline$\Sigma_{\mathrm{PAH}}$ in oil, ppm & 400 & 460 & 510 & 550 & 890 & 870 & 1100 & 1400 \\
\hline$\Sigma_{\text {naph }}$ in oil, ppm & 44 & 58 & 12 & 9.0 & 74 & 56 & 180 & 250 \\
\hline$\Sigma_{\text {phen }}$ in oil, ppm & 230 & 270 & 450 & 370 & 590 & 580 & 530 & 760 \\
\hline BaP in oil, ppm & 8.5 & 6.7 & 9.7 & 9.2 & 5.3 & 3.2 & 9.3 & 9.8 \\
\hline The $\mathrm{An} /(\mathrm{An}+\mathrm{Ph})$ ratio & 0.26 & 0.34 & 0.12 & 0.11 & 0.12 & 0.11 & 0.12 & 0.10 \\
\hline The Flu/(Flu + Pyr) ratio & - & - & 0.23 & 0.21 & 0.32 & 0.31 & 0.32 & 0.30 \\
\hline
\end{tabular}

\subsection{Assessment of Baikal water pollution near the deep oil seep}

The area of the water surface covered with oil slicks at the site of the oil seepage near Cape Gorevoy Utes in 2016 and 2019 did not change in comparison with the 2005 data (Khlystov et al., 2007) and was 1 $\mathrm{km}^{2}$. In the surface water layer (without oil slicks), the $\Sigma_{\text {alk }}$ concentration almost has not changed over 15 years since the discovery of this phenomena and ranges from 0.3 to $8.3 \mu \mathrm{g} / \mathrm{L}$, with an average value of $3.6 \mu \mathrm{g} / \mathrm{L}$ and median of $3.0 \mu \mathrm{g} / \mathrm{L}$ (Fig. 3). Except for some samples, for example, from the $200 \mathrm{~m}$ layer at station R4, the concentration of the detected $n$-alkanes does not exceed the maximum permissible concentration $\left(\mathrm{MPC}_{\text {fish }}\right.$ $=50 \mu \mathrm{g} / \mathrm{L}$ ) established for monitoring petroleum hydrocarbons in water bodies of fishery importance
(The list of fishery standards..., 1999) and is 25 to 40 times lower than the concentration of aliphatic hydrocarbons in the waters of the Atlantic and Southern oceans (Nemirovskaya, 2004).

Oil can enter the water column from different channels, such as asphalt structures resulting from oil fractionation at the water-bottom interface (Gorshkov et al., 2020), cracks and faults at the bottom of the lake, emitting separate oil balls at the bottom of the lake (Khlystov et al., 2009). In the latter case, the oil may enter the water column with minimal fractionation. The detection of extreme concentrations of $n$-alkanes and PAHs in the sample from the $200 \mathrm{~m}$ layer (station R4) may be the result of a similar oil discharge to lake waters and inclusion into the sample of water hydrocarbon plume that ascended through the water column to the surface of the lake. 
The fraction of PAHs in the water column did not contain high molecular weight polyarenes with carcinogenic properties (BaP and DahA). In particular, $\mathrm{BaP}$ was not identified above the $0.02 \mathrm{MPC}$, which is established for this pollutant in drinking water: $\mathrm{MPC}_{\mathrm{EU}}$ $\mathrm{BaP}=10 \mathrm{ng} / \mathrm{L}$ (Council Directive 98/83/EC, 1988); $\mathrm{MPC}_{\text {RUSSIA }} \mathrm{BaP}=5 \mathrm{ng} / \mathrm{L}$ (SanPIN 2.1.4.1074-01.2001, 2002).

For PAHs found in the water column, total toxic equivalent ( $\Sigma$ TEQ) values ranged from 0.004 to 0.110 ng/L (Fig. 4). The maximum $\Sigma T E Q$ values were observed for the PAH fraction in the bottom water layer ( 860 $\mathrm{m}$ ), in which naphthalenes dominated. Contribution of naphthalenes to $\Sigma$ TEQ is rated at $50-60 \%$. The presence of $\mathrm{An}, \mathrm{Chr}$ and $\mathrm{BbF}$ in water, which have relatively high toxicity coefficients (TEFs), also significantly contribute to the total TEQ of PAHs in this water layer. On a water surface covered with oil slicks, the toxicity of PAHs reaches a total TEQ of $100-200 \mathrm{ng} / \mathrm{L}$. In the water of the upper water layer $(5 \mathrm{~m})$, $\Sigma$ TEQ does not exceed $0.110 \mathrm{ng} / \mathrm{L}$. Deep water (R4, $400 \mathrm{~m}$ ) is characterised by a minimum level of total TEQ $(0.004 \mathrm{ng} / \mathrm{L})$, which is comparable to the toxicity assessment of PAHs in water samples collected at the reference station in the Baikal pelagic zone. In the absence of oil slicks on the water surface (station R6, $0 \mathrm{~m}$ ), the $\Sigma$ TEQ of PAHs is 0.055 ng/L. (St.3; Fig. 1).

The distribution of petroleum hydrocarbons in Baikal water from the site of deep seepage is limited, and water pollution is localised. The total concentrations of $n$-alkanes at the reference station (St.1, $\Sigma_{\text {alk }} \leq 0.15 \mu \mathrm{g} / \mathrm{L}$; Russell and Rosell-Mele, 2005; Gorshkov et al., 2010) are up to 35 times lower than the maximum alk concentrations found in the water column and on the water surface near Cape Gorevoy Utes. PAH concentrations in the surface water layer at sites without oil slicks on the surface and deep layers are comparable with $\Sigma_{\mathrm{PAH}}$ concentrations at reference stations and in the pelagic zone (7.0-36 ng/L; Gorshkov et al., 2018).

The low level of water pollution due to petroleum hydrocarbons near deep oil seepage sites is associated with natural mechanisms in the Baikal ecosystem. Microorganisms and phytoplankton make a decisive contribution to the purity of Baikal water, and oil fractionation during deep discharge contributes to the bioavailability of petroleum hydrocarbons. Model experiments indicated that during the cultivation of Baikal microorganisms in the presence of oil as a carbon source, $n$-alkanes and PAHs effectively degrade. Moreover, diatoms Synedra acus subsp. radians, the dominant species of Baikal phytoplankton, accumulate PAHs in their lipid bodies (Pavlova et al., 2005; 2012; Shishlyannikov et al., 2017; Gorshkov et al., 2020).

In the model experiments on oil degradation, there was no selective destruction of $n$-alkanes, and conversion of the fraction of normal hydrocarbons showed a simultaneous decrease in the content of all homologues. Therefore, the dominance of light $n$-alkanes in the water at sites with oil seepage is likely to be the result of oil fractionation at the bottom-water interface.

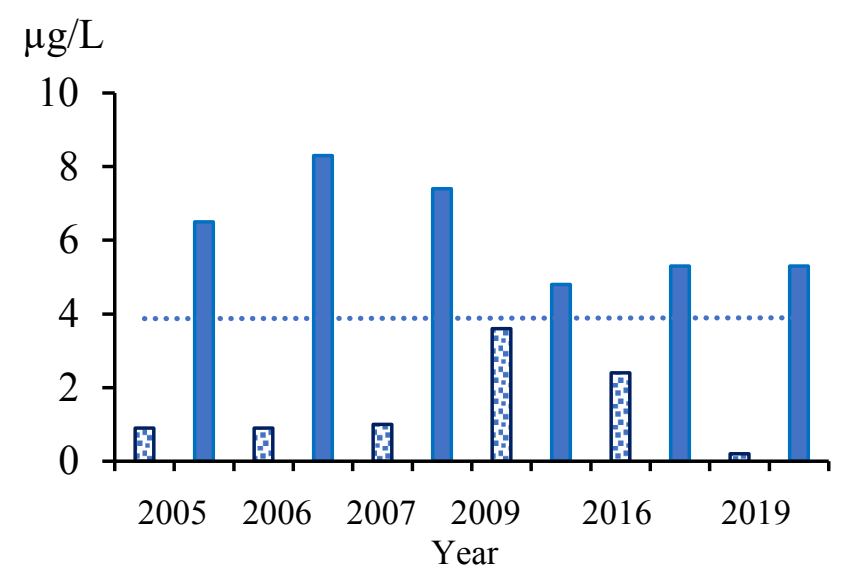

Fig.3. The trend of the content of n-alkanes in the surface water layer (without oil slicks) near the oil seep in 2005 - 2019, minimum and maximum $\Sigma_{\text {alk }}$ concentrations, MPCfish $=50 \mu \mathrm{g} / \mathrm{L}$

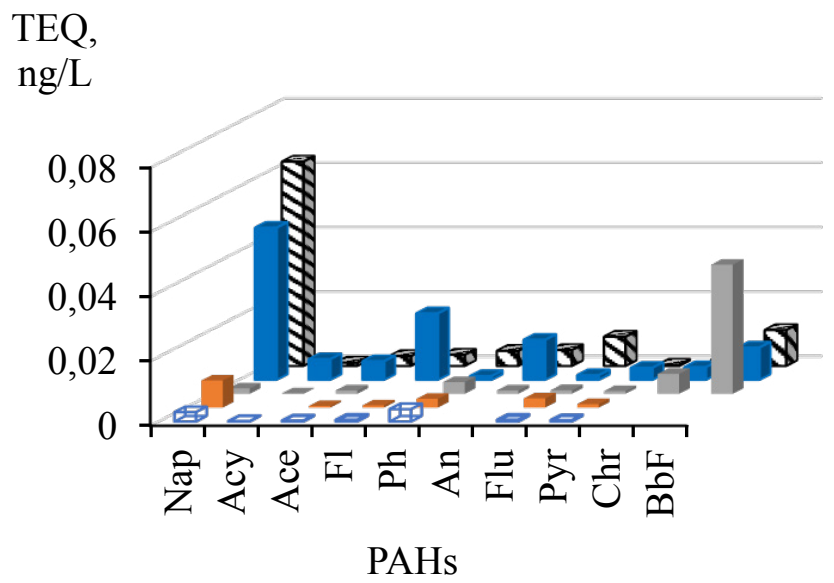

Fig. 4. Toxicity assessment of PAHs in the water column at the site of the oil seepage near Cape Gorevoy Utes:

- station R4, $400 \mathrm{~m}: \Sigma_{\mathrm{PAH}} 14 \mathrm{ng} / \mathrm{L}, \Sigma \mathrm{TEQ} 0.004$;

- station R6, $0 \mathrm{~m}: \Sigma_{\mathrm{PAH}} 14 \mathrm{ng} / \mathrm{L}, \Sigma \mathrm{TEQ} 0.055$;

- station R10, $5 \mathrm{~m}: \Sigma_{\mathrm{PAH}} 90 \mathrm{ng} / \mathrm{L}, \Sigma \mathrm{TEQ} 0.113$;

- station R7, $860 \mathrm{~m}: \Sigma_{\mathrm{PAH}} 100 \mathrm{ng} / \mathrm{L}, \Sigma \mathrm{TEQ} 0.100$

- station St.3, 5-1500 $\mathrm{m}$ (reference station in the Lake Baikal pelagic zone): $\Sigma_{\mathrm{PAH}} 10-27 \mathrm{ng} / \mathrm{L}, \Sigma \mathrm{TEQ}$ 0.013-0.018

Perhaps, the ability to degrade hydrocarbons is fixed in the genomes of Baikal microorganisms inhabiting areas of natural oil seepage (Likhoshvay et al., 2013; Lomakina et al., 2014), because, owing to geological processes, oil and its deformation products are permanent components in the ecosystem of the east coast of the Central Baikal basin. Additionally, Baikal microorganisms synthesise surfactants (Pavlova et al., 2010); hence, biosurfactants can contribute to the sorption of hydrocarbons on suspended particles in Baikal water and subsequent deposition on the lake bottom.

The presence of $n$-alkanes and PAHs in Baikal water is due to not only natural sources but also technogenic sources, i.e. surface runoff, emissions 
from vessels of the Baikal fleet, and emissions into the atmosphere from industrial enterprises along the coast. In the latter case, the $\Sigma_{\mathrm{PAH}}$ concentration in the surface water layer near the Listvyanka settlement can reach $160 \mathrm{ng} / \mathrm{L}$, and in the Selenga River delta, the total concentration of petroleum hydrocarbons was 16-78 $\mu \mathrm{g} / \mathrm{L}$ (St.1, St.2; Gorshkov et al., 2010).

\section{Conclusion}

The oil concentrates mainly on the water surface in the form of oil slicks. The area of the lake covered with oil slicks is $\sim 1 \mathrm{~km}^{2}$, and it almost has not changed since the discovery of oil seep in 2005. From 2005 to 2019, the concentration of $n$-alkanes in the surface water ranged between 0.2 and $8.3 \mu \mathrm{g} / \mathrm{L}$, with an average value of $3.6 \mu \mathrm{g} / \mathrm{L}$. The concentration of $n$-alkanes does not exceed $0.1 \mathrm{MPC}_{\text {fish }}\left(\mathrm{MPC}_{\text {fish }}=50\right.$ $\mu \mathrm{g} / \mathrm{L}$ ), which was established for monitoring petroleum hydrocarbons in water bodies of fishery importance. The $\Sigma_{\mathrm{PAH}}$ concentration was within the range from 1.0 to $110 \mathrm{ng} / \mathrm{L}$, and the fraction of PAHs detected there had no carcinogens. In particular, BaP was not identified above the 0.01-0.02 MPC, which had been established for this pollutant in drinking water $\left(\mathrm{MPC}_{\mathrm{EU}}\right.$ $\left.\mathrm{BaP}=10 \mathrm{ng} / \mathrm{L}, \mathrm{MPC}_{\mathrm{RUSSI}} \mathrm{BaP}=5 \mathrm{ng} / \mathrm{L}\right)$. The toxicity of PAHs in oil slicks on the water surface had the TEQ value from 100 to $200 \mathrm{ng} / \mathrm{L}$. For the PAHs found in the water column, TEQ values ranged from 0.004 to $0.110 \mathrm{ng} / \mathrm{L}$. Deep water $(400 \mathrm{~m})$ is characterised by a minimum level of total TEQ, which is comparable to the assessment of the toxicity of PAHs in water samples collected at the reference station in the Baikal pelagic zone. The distribution of petroleum hydrocarbons in Baikal water from the site of deep seepage is limited, and water pollution is localised. At reference stations in the Baikal pelagic zone, the total concentrations of $n$-alkanes in the surface water layer are up to 35 times lower than that at the seepage site. The concentrations of PAHs in the surface water layer and deep layers in the pelagic zone of Lake Baikal range from 7.0 to 36 $\mathrm{ng} / \mathrm{L}$.

\section{Acknowledgments}

This work was conducted within the framework of the State Task, projects No. 0345-2019-0007 (AAAAA16-116122110064-7) and No. 0345-2019-0008 (AAAA-A16-116122110065-4). The chromato-massspectrometric analysis was conducted at the Collective Instrumental Centre "Ultramicroanalysis".

\section{References}

Council Directive 98/83/EC of 3 November, 1988. 1988. On the quality of water in intended for human consumption» into the national laws in the EU association countries. Official Journal of the European Communities 5.

Golmshtok A.Y., Duchkov A.D., Hutchinson D.R. et al. 2000. Heat flow and gas hydrates of the Baikal Rift Zone. International Journal of Earth Sciences 89: 193-211. DOI: $10.1007 / \mathrm{s} 005319900071$
Gorshkov A.G., Grachev M.A., Zemskaya T.I. et al. 2006. Oil in Lake Baikal, paradox or regularity? In: International Congress on Analytical Sciences, pp. 375-376.

Gorshkov A.G., Marinayte I.I., Zemskaya T.I. et al. 2010. Modern level of petroleum products in water of Lake Baikal and its tributaries. Chemistry for Sustainable Development 18: 623-630.

Gorshkov A.G., Kustova O.V., Izosimova O.N. et al. 2018 POPs monitoring system in Lake Baikal - impact of time or the first need? Limnolgy and Freshwater Biology 1: 43-48. DOI: $10.31951 / 2658-3518-2018-A-1-43$

Gorshkov A.G., Pavlova O.N., Khlystov O.M. et al. 2020. Fractioning of petroleum hydrocarbons from seeped oil as a factor of purity preservation of water in Lake Baikal. Journal of Great Lakes Research 46: 115-122. DOI: 10.1016/j. jglr.2019.10.010

Hazen T.C., Dubinsky E.A., DeSantis T.Z. et al. 2010. Deep-sea oil plume enriches indigenous oil-degrading bacteria. Science 330: 204-208. DOI: 10.1126/science.119597

Kashirtsev V.A., Kontorovich A.E., Moskvin V.I. et al. 2006. Terpanes from oil shows of Lake Baikal. Petroleum Chemistry 46: 217-224. DOI: 10.1134/S0965544106040013

Khlystov O.M., Gorshkov A.G., Egorov A.V. et al. 2007. Oil in the lake of world heritage. Doklady Earth Sciences 414: 635-659. DOI: 10.1134/S1028334X07050042

Khlystov O.M., Zemskaya T.I., Sitnikova T.Y. et al. 2009. Bottom bituminous constructions and biota inhabiting them according to investigation of Lake Baikal with the mir submersible. Doklady Earth Sciences 429: 1333-1336. DOI: 10.1134/S1028334X09080200

Kontorovich A.E., Kashirtsev V.A., Moskvin V.I. et al. 2007. Petroleum potential of Baikal deposits. Russian Geology and Geophysics 48: 1046-1053. DOI: 10.1016/j.rgg.200 7. 11.004

Likhoshvay A., Khanaeva T., Gorshkov A. et al. 2013. Do oil-degrading Rhodococci contribute to the genesis of deepwater bitumen mounds in Lake Baikal? Geomicrobiology Journal 30: 209-213. DOI: 10.1080/01490451.2012.665149

Lomakina A.V., Pogodaeva T.V., Morozov I.V. et al. 2014. Microbial communities of the discharge zone of oil- and gas-bearing fluids in low-mineral Lake Baikal. Microbiology 83: 278-287. DOI: 10.1134/S0026261714030126

Nemirovskaya I.A. 2004. Uglevodorody v okeane (sneg - led - voda - vzves' - donnyye osadki) [Hydrocarbons in the ocean (snow-ice-suspended matter-bottom sediments)]. Moscow: Nauchnyj Mir. (in Russian)

Nisbet I.C.T., LaGoy P.K. 1992. Toxic equivalency factors (TEFs) for polycyclic aromatic hydrocarbons (PAHs). Regulatory Toxicology and Pharmacology 16: 290-300. DOI: 10.1016/0273-2300(92)90009-x

Pavlova O.N., Parfenova V.V., Zemskaya T.I. et al. 2005. Biodegradation of oil and hydrocarbon by microbial community of Lake Baikal. In: The IV-th Vereshchagin Baikal Conference, p. 147. (in Russian)

Pavlova O.N., Lomakina A.V., Likhoshvay A.V. et al. 2010. Microbial communities in areas of natural oil outflow on Lake Baikal. Uspekhi Nauk o Zhizni [Successes in Life Sciences] 2: 169-172. (in Russian)

Pavlova O.N., Lomakina A.V., Gorshkov A.G. et al. 2012. Microbial communities and their ability to oxidize n-alkanes in the area of release of gas and oil containing fluids in mid-Baikal (cape Gorevoi Utes). Biology Bulletin 39: 458-463. DOI: $10.1134 /$ S1062359012050123

Russell M., Rosell-Mele A. 2005. Preliminary study of fluxes of major lipid biomarker classes in the water column and sediments of Lake Baikal, Russia. Global and Planetary Change 46: 45-56. DOI: 10.1016/j.gloplacha.2004.11.005

SanPIN 2.1.4.1074-01.2001. 2002. Drinking water. Hygienic requirements water quality of centralised drinking 
water supply systems. Quality control. Resolution No 24. September 26. (in Russian)

Shishlyannikov S.M., Nikonova A.A., Klimenkov I.V. et al. 2017. Accumulation of petroleum hydrocarbons in intracellular lipid bodies of the freshwater diatom Synedra acus subsp. Radians. Environmental Science Pollution Research 24: 275-283. DOI: 10.1007/s11356-016-7782-y

Simoneit B.R.T., AboulKassim T.A.T., Tiercelin J.J., 2000. Hydrothermal petroleum from lacustrine sedimentary organic matter in the East African Rift. Applied Geochemistry 15: 355-368. DOI: 10.1016/S0883-2927(99)00044-X

The list of fishery standards for maximum permissible concentrations (MPC) and tentatively safe exposure levels (SEC) of harmful substances for water of water bodies of fishery importance. 1999. Moskow: VNIRO. (in Russian)

Vila J., Nieto J.M., Mertens J. et al. 2010. Microbial community structure of a heavy fuel oil-degrading marine consortium: linking microbial dynamics with polycyclic aromatic hydrocarbon utilization. FEMS Microbial Ecology 73: 349-362. DOI: 10.1111/j.1574-6941.2010.00902.x

Zarate-del Valle P.F., Rushdi A.I., Simoneit B.R.T. 2006. Hydrothermal petroleum of Lake Chapala, Citala Rift, western Mexico: bitumen compositions from source sediments and application of hydrous pyrolysis. Applied Geochemistry 21: 701-712. DOI: 10.1016/j.apgeochem.2006.01.002

Yender R., Stanzel K. 2011. Tanker SOLAR 1 Oil spill, Guimaras, Philippines: impacts and response challenges. In: Fingas M.F. (Ed.), Oil spill science and technology. Prevention, response, and cleanup. Burlington, pp. 1133-1146.

Yunker M.B., Macdonald R.W., Vingarzan R. et al. 2002. PAHs in the Fraser River basin: a critical appraisal of PAH ratios as indicators of PAH source and composition. Organic Geochemistry 33: 489-515. DOI: 10.1016/ S0146-6380(02)00002-5 